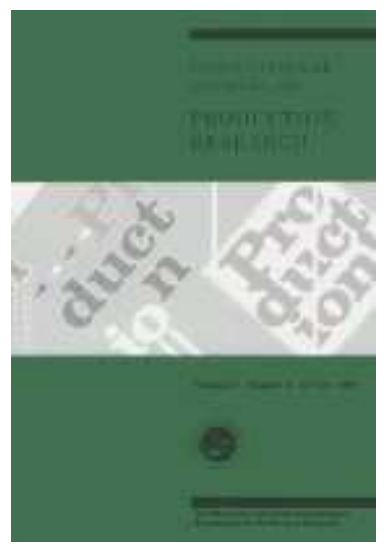

\title{
Performance measurement using overall equipment effectiveness (OEE): Literature review and practical application discussion
}

\begin{tabular}{|r|l|}
\hline Journal: & International Journal of Production Research \\
\hline Manuscript ID: & TPRS-2006-IJPR-0559.R1 \\
\hline Manuscript Type: & State-of-the-Art Review \\
\hline $\begin{array}{r}\text { Date Submitted by the } \\
\text { Author: }\end{array}$ & 27-Nov-2006 \\
\hline Complete List of Authors: & $\begin{array}{l}\text { Pintelon, Liliane; KULeuven, CIB } \\
\text { muchiri, peter; KULeuven, CIB }\end{array}$ \\
\hline Keywords: & MAINTENANCE MANAGEMENT, PERFORMANCE MEASURES \\
\hline Keywords (user): & \\
\hline
\end{tabular}

\section{s scholarONE" \\ Manuscript Central}




\title{
Title: Performance Measurement Using Overall
}

\section{Equipment Effectiveness (OEE): Literature Review}

\author{
\& Practical Application Discussion
}

\author{
Article Type: Review Article
}

\section{Authors:}

\author{
Peter Muchiri*, Liliane Pintelon, \\ Centre for Industrial Management (CIB) \\ Katholieke Universiteit Leuven \\ Celestijnenlaan 300A \\ 3001 Heverlee, Belgium
}

Tel: +3216322844

Fax: +32 16322986

*Corresponding Author: peter.muchiri@cib.kuleuven.be

liliane.pintelon@cib.kuleuven 


\begin{abstract}
The quest for improving productivity in the current global competitive environment has led to a need for rigorously defined performance measurement systems for manufacturing processes. In this paper, OEE is described as such kind of performance measurement tool that measures different types of production losses and indicates areas of process improvement. Analysis is done on how OEE has evolved leading to other tools like TEEP, PEE, OFE, OPE and OAE. Two industrial examples of OEE application are discussed and the differences between theory and practice analysed. Finally, a framework for classifying and measuring production losses for overall production effectiveness is proposed. The framework harmonises the differences between theory and practice and makes possible the presentation of overall production /asset effectiveness (OAE) that can be customized with the manufacturers needs to improve productivity.
\end{abstract}

Keywords: Performance Measurement, Overall Equipment Effectiveness, , Manufacturing 


\section{Introduction}

The evolution towards a global economy has expanded the base of competition for virtually all businesses. By the very nature of the word competition, it is implied that someone out there is always keeping score. The tally on the scorecard may be a measure of more sales, increased profit or a growing customer base. Regardless of the criteria of measurement used, to remain competitive, you have to put up more points on the board. In order to beat competition, there is a basic business demand to get better at what is done and at meeting customers' expectation.

As noted by Fleischer et al (2006), the competitiveness of manufacturing companies depends on the availability and productivity of their production facilities. Huang et al (2003) also states that due to intense global competition, companies are striving to improve and optimize their productivity in order to remain competitive. This would be possible if the production losses are identified and eliminated so that the manufacturers can bring their products to the market at a minimum cost. This situation has led to a need for a rigorously defined performance measurement system that is able to take into account different important elements of productivity in a manufacturing process.

The total productive maintenance (TPM) concept, launched by Nakajima (1988) in the 1980s, provided a quantitive metric called Overall Equipment Effectiveness (OEE) for measuring productivity of individual equipment in a factory. It identifies and measures losses of important aspects of manufacturing 
namely availability, performance and quality rate. This supports the improvement of equipment effectiveness and thereby it's productivity. The OEE concept is becoming increasingly popular and has been widely used as a quantitative tool essential for measurement of productivity especially in the semiconductor manufacturing operations (Huang et al, 2003). Manufacturers in other industries have also embraced it to improve their asset utilization.

The industrial application of OEE, as it is today, varies from one industry to another. Though the basis of measuring effectiveness is derived from the original OEE concept, manufacturers have customized OEE to fit their particular industrial requirements. Furthermore, the term OEE has been modified in literature to different other terms with regard to the concept of application. This has led to broadening of OEE to overall factory /plant effectiveness (OFE) / (OPE), overall throughput effectiveness (OTE), production equipment effectiveness (PEE), overall asset effectiveness (OAE) and total equipment effectiveness performance (TEEP).

It is the objective of this paper to investigate how the OEE tool has evolved with time and how it has been applied to fit the individual needs of the industries. Two industrial examples are analysed to show how OEE concept is applied to enhance productivity in industries and the different types of production losses measured. To harmonise the different OEE concepts in literature and practice, a general framework with different categories of production losses has been developed. This framework gives different categories of losses that are important in measuring overall production effectiveness. Finally, this paper 
discusses the benefits and challenges of using OEE measurement tool and the type of processes where its benefits is significant.

\section{The OEE Measurement Tool - Overview}

OEE measurement tool was developed from the TPM concept launched by Nakajima (1988). The goal of TPM is to achieve zero breakdown and zero defects related to equipment. The consequence of reducing breakdowns and defects is improvement on production rate, reduction in costs, reduction in inventory and eventually, increase in labour productivity. The TPM concept puts much attention to production equipments since they have a high influence on quality, productivity, cost, inventory, safety and health, and production output. This is especially true for highly automated processes.

OEE is defined as a measure of total equipment performance. That is, the degree to which the equipment is doing what it is supposed to do (Williamson, 2006). It is a three-part analysis tool for equipment performance based on its availability, performance, and the quality rate of the output. It is used to identify for an equipment the related losses for the purpose of improving total asset performance and reliability. It categorizes major losses or reasons for poor performance and therefore provides the basis for setting improvement priorities and beginning of root cause analysis. It can point to hidden capacity in a manufacturing process and lead to balanced flow. OEE is used to track and trace improvements or decline in equipment effectiveness over a period of time (Bulent et al, 2000). 
Confusion exist as to whether OEE indeed measures effectiviness (as depicted by its name) or it is an efficiency measure. In literature (US department of Energy, 1995), effectiveness is defined as a process characteristic that indicates the degree to which the process output conforms to the requirements. It tells whether right things are done. Efficiency on the other hand, is defined as a process characteristic indicating the degree to which the process produces the required output at minimum resource cost. It tells whether things are done right. The three measures (availability rate, performance rate and quality rate) captured by the OEE tool indicates the degree of conformation to output requirements. Therefore, indeed the OEE tool is a measure of effectiveness. This is in agreement with the definition in literature that OEE measures the degree to which the equipment is doing what it is supposed to do based on availability, performance and quality rate. (Williamson, 2006).

The OEE tool is designed to identify losses that reduce the equipment effectiveness. These losses are activities that absorb resources but create no value. According to Jonsson and Lesshammar (1999), the losses are due to manufacturing disturbances that are either chronic or sporadic. Chronic disturbances are small, hidden and are as a result of several concurrent causes. Sporadic disturbances on the other hand, are more obvious since they occur quickly and have large deviations from the normal state. It is a bottom-up approach where an integrated workforce strives to achieve overall equipment effectiveness by eliminating six big losses (Nakajima, 1988). The six big losses 
are given below with some examples from a palletizing plant in a brewery as analysed by Pintelon et al (2000).

Downtime losses

(1) Breakdown losses categorised as time losses and quantity losses caused by equipment failure or breakdown. For example, a breakdown of palletizing plant motor in a brewery leads to downtime and thus production loss.

(2) Set-up and adjustment losses occur when production is changing over from requirement of one item to another. In brewery plant, this type of loss is encountered during set-ups between different products, testing during start-ups and fine-tuning of machines and instruments.

Speed losses

(3) Idling and minor stoppage losses occur when production is interrupted by temporary malfunction or when machine is idling. For example dirty photocells on palletizing machines cause minor stoppages. Though they are quickly fixed, much capacity is lost due to their frequency.

(4) Reduced speed losses refer to the difference between equipment design speed and actual operating speed. In a palletizing plant, use of unadapted pallets cause longer processing time for the same number of bottles leading to speed losses.

Quality Losses

(5) Quality defects and rework are losses in quality caused by malfunctioning production equipment. For example, some pallet types get stuck in between depalletizer and unpacker and are damaged. 
(6) Reduced yield during start-up are yield losses that occur from machine start-up to stabilisation. For example in the brewery, poor preparation for morning shift by night shift leads to problems with the filling taps and thus leads to reduced yields.

The six big losses are measured by OEE, which is a function of availability (A), performance $(P)$ and Quality rate $(\mathrm{Q})$. Therefore:

$$
O E E=A * P * Q
$$

Where,

$$
\begin{aligned}
& \text { Availability Rate }(\mathrm{A})=\frac{\text { Operating Time }(\mathrm{hrs})}{\text { Loading time }(\mathrm{hrs})} \times 100 \\
& \text { Operating Time }=\text { Loading Time }- \text { Downtime } \\
& \text { Performance Efficiency }(\mathrm{P})=\frac{\text { Theoretical Cycle time (hrs)*Actual Output (Units) }}{\text { Operating Time (hrs) }} \\
& \text { Quality Rate }(\mathrm{Q})=\frac{(\text { Total Production }- \text { Defect Amount) }}{\text { Total Production (Units) }} \times 100
\end{aligned}
$$

The OEE measurement tool has its strength in the way it integrates different important aspects of manufacturing into a single measurement tool. The perspectives integrated in the OEE tool are the maintenance effectiveness, production efficiency and quality efficiency as shown in figure 1 . 


\section{'[Insert Figure 1 here]'}

\section{Evolution Of OEE}

Though the OEE tool has become increasingly popular and has been widely used as a quantitative tool essential for measurement of productivity, it is only limited to productivity behaviour of individual equipments (Huang et al, 2003). Scott and Pisa (1998) have pointed out that the gains in OEE, while important and on going, are insufficient because no machine is isolated. They points out that manufacturing process is a complex web of interactions among process tools, materials, machines, people, departments, companies and processes. However, too often these inter-dependent activities are viewed in isolation and there is lack of coordination in deploying available factory resources (people, information materials and tools) to manage work efficiently. It is therefore necessary to focus one's attention beyond the performance of individual equipment toward performance of the whole factory. The ultimate objective of any factory is to have a highly efficient integrated system and not brilliant individual equipments (Oechsner et al, 2003).

This insufficiency of OEE tool has led to modification and enlargement of original OEE tool to fit a broader perspective as deemed important in the manufacturing systems. With the modification of OEE, different terminologies has also come up in literature and in practice, coupled with their modified formulations. Some of the modified formulations are limited to effectiveness at equipment level (e.g. PEE and TEEP) while others have been extended to 
factory level effectiveness (e.g. OFE, OTE, OPE and OAE). This paper looks into these different terminologies and formulations developed in literature. Further, two industrial examples are discussed as an illustration of industrial practice concerning OEE. This has been done using examples from 2 Western European companies. The different terminologies and consequent formulations are as follows:

\subsection{Total Equipment Effectiveness Performance (TEEP)}

Total Equipment Effectiveness Performance (TEEP), proposed by Invancic (1998), is very similar to OEE. The main difference lies in the inclusion of planned downtime in total planned time horizon. In order to show clearly how maintenance contributes to the bottom line productivity of the plant, a clear distinction is made between planned downtime and unplanned downtime. Minimising unplanned shutdown, sometimes called technical downtime, is a common goal in maintenance. Unplanned downtime is a function of the number of breakdowns within a specified time period and related measures such as mean time between failures (MTBF) and mean time to repair (MTTR) (Pintelon et al, 2000). MTBF and MTTR are claimed to be measures of equipment achievement and are related to objectives such as functional performance and process capability (Wilson, 1999).

With the help of TEEP, planned and unplanned downtime can be measured. Thorough analysis of these two elements enables the maintenance function to improve equipments availability by either increasing the mean time between 
failure (MTBF) or reducing the mean time to repair (MTTR). The other elements included in the TEEP measure are the speed losses and quality rate, which are also in OEE. The TEEP is calculated by dividing the valuable operating time (VOT) with the total available time $\left(T_{T}\right)$ as shown in figure 2 . The constituent elements (losses) in TEEP are analysed and measured as shown in figure 3.

\section{'[Insert Figure 2 here]'}

The TEEP measure, like OEE, is limited to equipment level productivity. It is also applicable to a processing plant or a flow shop where the production process can be treated like a single production entity.

\section{'[Insert Figure 3 here]'}

\subsection{Production Equipment Effectiveness (PEE)}

Production equipment effectiveness (PEE), formulated by Raouf (1994), is similar to OEE. The main difference with OEE is the allocation of weights to the various items in the overall effectiveness. It assumes that quality has different weight from performance and different from availability contrary to the basic assumption in OEE that the three elements have the same weight. It also makes a distinction between two different types of production operations namely:

1. Discrete-type production operations and

2. Continuous process operation. 
For discrete-type production operation, PEE is calculated as follows:

$$
\begin{array}{ll}
\text { Where, } \quad & \mathrm{PEE}=\left(\mathrm{A}^{\kappa 1}\right)\left(\mathrm{E}^{\kappa 2}\right)\left(\mathrm{Q}^{\kappa 3}\right) \\
& \mathrm{E}=\text { Availability } \\
& \mathrm{Q}=\text { Performance Efficiency }
\end{array}
$$

$\kappa_{i}$ is the weights of the PEE elements (for $i=1$ to 3 ), $0<\kappa_{i} \leq 1$ and $\sum \kappa_{i}=1$

For continuous process operation, PEE is defined as function of availability $\left(A_{1}\right)$, attainment $\left(A_{2}\right)$, performance efficiency $(E)$, quality rates $(Q)$, product support efficiency (PSE) and operating utility (OU). These losses are outlined in PEE diagram as shown in figure 4. Therefore:

$$
\mathrm{PEE}=\left(\mathrm{A}_{1}\right)^{\kappa 1}\left(\mathrm{~A}_{2}\right)^{\kappa 2}(\mathrm{E}){ }^{\kappa 3}(\mathrm{Q})^{\kappa 4}(\mathrm{PSE}){ }^{\kappa}(\mathrm{OU})^{\kappa 6}
$$

Where,

$\kappa_{i}$ is the weights of the PEE elements (for $i=1$ to 6 ), $0<\kappa_{i} \leq 1$ and $\sum \kappa_{i}=1$

\section{'[Insert Figure 4 here]'}

The availability rate considers the planned or scheduled downtime and is similar to the planning rate in TEEP. The attainment rate considers the unscheduled downtime and is similar to availability in TEEP. The other additional factors included are the product support efficiency and operating utility, which considers the transaction losses and no demand time respectively. It is assumed that there 
is no setup time needed for the continuous process operation and therefore, setup time loss has not been included in the PEE diagram.

\subsection{Overall Factory Effectiveness (OFE)}

The overall factory effectiveness (OFE) was developed to measure the factory level effectiveness, where several production steps or machines are installed to form a production process. While OEE is about achieving excellence in individual equipment, OFE is about the relationships among different machines and processes. As noted by Scott and Pisa (1998), OFE seeks to integrate the many activities and information systems that production process entails. OFE is therefore a term about combining activities, relationships between different machines and processes, integrating information, decisions, and actions across many independent systems and subsystems (Oechsner et al, 2003). Among the issues that OFE seeks to accomplish is; to synchronize the production schedule with planned downtime, setup time and qualification time through tighter connectivity to enterprise planning systems and infinite capacity schedule; optimize the sequence of orders, works or jobs; ensure a balanced line and smooth flow of work by integrating micro-scheduling with overall plant scheduling (Williamson, 2006).

Up to now, there is no common approach for the OFE metrics. However, some proposals are given in literature of which two are discussed. The approach of Scott and Pisa (1998) considers the fact that different plants have different goals and so there can be no single indicator. They suggest creating a 
composite metrics (e.g. cycle time efficiency, on-time delivery, capacity utilization, rework arte, yield rate etc) that ask for specific key goals. The important thing is to define measuring criteria for success and application of weight factors as desired to meet corporate goals. For these metrics, an overall result is computed.

Another approach proposed by Huang et al (2003) considers simulation analysis as the most reliable method in studying the dynamic performance of manufacturing systems. It defines an OFE metric, overall throughput effectiveness (OTE), developed on the basis of OEE metrics analysis, for complex connected manufacturing systems. These metrics are integrated with simulation analysis for manufacturing productivity improvement.

From the OEE formula and the OEE diagram (see figure 1), OEE is calculated in terms of production units as;

$$
\mathrm{OEE}=\frac{\text { Number of good parts produced }\left(\mathrm{P}_{\mathrm{g}}\right)}{\text { Theoretical number of parts produced in total time }\left(\mathrm{P}_{\mathrm{th}}\right)}
$$

Where,

$$
\mathrm{P}_{\mathrm{th}}=\text { Theoretical production rate }\left(\mathrm{R}_{\mathrm{th}}\right) * \text { Total available time }\left(\mathrm{T}_{\mathrm{T}}\right)
$$

By extending the expression of unit-based OEE to factory level, the overall throughput effectiveness (OTE) during period $\mathrm{T}_{\mathrm{T}}$ is defined as; 


$$
\mathrm{OTE}=\frac{\text { Good product output (units) from factory }\left(\mathrm{P}_{\mathrm{g}(\mathrm{F})}\right)}{\text { Theoretical attainable product output (units) from factory in total time }\left(\mathrm{P}_{\mathrm{F}(\mathrm{th})}\right)}
$$

Similarly,

$$
P_{t h(F)}=R_{t h(F)} . T_{T}
$$

Where,

$R_{\operatorname{th}(F)}=$ The theoretical processing rate for actual product output from factory.

Using these formulations, OFE for any manufacturing system can be calculated. Since many manufacturing systems are parallel and/or series the OTE formulation for these two systems have been developed.

It is however noted that the OFE metric are in development stage and simulation analysis is considered the most reliable method to date in studying the dynamic performance of manufacturing systems (Huang et al, 2003). The under laying concept behind simulation is that manufacturing systems can be treated as a combination of a number of simple subsystems, which in turn are the combination of individual production equipments (Huang, 2002). Productivity metrics are then integrated in the model to measure system performance and help identify productivity improvement opportunities.

\subsection{OAE and OPE}


OAE (overall asset effectiveness) and OPE (overall production effectiveness) are measurement tools that have been developed from OEE tool. Though the terms have limited application in literature, they have been applied extensively in the industries. They are applied to identify and measure all the losses associated with the overall production process. The two terms have the same meaning with regards to industrial application. However, the elements or losses measured differ from one industry to another. Production losses are measured by either measuring time losses or production output losses.

Two industrial examples of OAE/OPE application are discussed. The two companies are multinationals located in western Europe and their identities are left anonymous in this paper. For the two industrial examples, a study was done on the structure of their OAE diagram and the type of production losses it measures. However, the study did not involve detailed case study on the dynamics of data collection.

\subsection{Industrial Examples of OAE Application.}

\subsection{Company A}

Company $A$ is a chemical processing company. The OAE tool is used with the objective of maximizing the production output and minimizing losses of all types. The company, therefore, use the production output (tonnage) approach in the OAE tool to identify the losses. 
The maximum output that the company is able to produce at optimum capacity is defined as the theoretical maximum tonnage $\left(\mathbf{T}_{\mathbf{T}}\right)$. This is the maximum production capacity that the plant is able to attain expressed as a quantity related to time unit: an hour, a day, a week, a month or a year. The optimum operation of a plant is reduced in several circumstances by production losses (PL). Instead of the anticipated theoretical tonnage $\mathbf{T}_{\mathbf{T}}$, the plant delivers an actual tonnage $\mathbf{T}_{\text {ACT }}$ corresponding to the tonnage actually produced within the commercial specifications. Therefore,

Production Losses, $\mathrm{PL}=\mathrm{T}_{\mathrm{T}}-\mathrm{T}_{\mathrm{ACT}}$

The identifiable production losses are grouped in the following categories;

\section{PL com}

These are production losses related to commercial demand. These are the result of plant shutdowns, lower production rates, or production overcapacity compared to commercial demand. They also include the quantity of out of specification product attributable to adjusted operating rate.

\section{2. $\mathrm{PL} \mathrm{CH}$}

The production schedule provides for consecutive production of products with different characteristics. The changeover entails slower production or stoppage to adjust the operating parameters, or swap equipments and tools. The result is a production loss $\left(\mathrm{PL}_{\mathrm{CH}}\right)$ compared to continued operation with the same 
product. In addition, this situation frequently results in quantities of product that don't meet quality specifications and are also entered under $\mathbf{P L}_{\mathrm{CH}}$.

\section{3. $\mathrm{PL} F$}

These are the production losses resulting from poor reliability. Two different types of poor reliability may occur:

(a) PL FE - These are production losses due to external causes that are totally outside the company's control. This may be due to:

- Third party failure to supply

- Shortage of energy (electricity, gas, etc.)

- Supply problems resulting from logistics (e.g. railways, road haulers, sea or waterway transport).

- Exceptional poor weather conditions

(b) $\mathrm{PL}_{\mathrm{Fl}}$ - These are production losses due to internal causes for which the company is accountable. These production losses result from production slowdowns or stoppages as a result of the following occurrences:

- Equipment failure.

- Utility shortage.

- Labor unrest.

- Organization problems.

- Safety, health and environmental problems.

- Mandatory planned shutdowns.

- Operation errors

- Planned shutdown due to capital expenditure work 


\section{PL OP}

These are production losses related to poor operation performance. Causes may be due to problems relating to process, equipment performance degradation through aging or losses associated with shutdown or start-up difficulties (especially after major shutdowns).

\section{5. $\mathrm{PL} Q$}

These are losses due to quality of the products (failure to produce product within specification). It includes all products out of specification due to technical or commercial reasons (except out of specification products related to $\mathrm{PL}_{\mathrm{com}}$ and $\mathbf{P} \mathbf{L}_{\mathrm{CH}}$ ), as well as quantities of recycled product.

The production losses are presented in the OAE diagram as shown in figure 5. From the OAE diagram, overall asset effectiveness (OAE) and operating asset utilization (OAU) are calculated as follows:

$$
\text { Overall Asset Effectiveness, OAE }=\frac{T_{A C T}}{T_{T}}
$$

$$
\text { Operating Asset Utilization, OAU }=\frac{\mathrm{T}_{\mathrm{ACT}}}{\mathrm{T}_{\mathrm{T}}-\mathrm{PL} \mathrm{COM}_{\mathrm{C}}}
$$

\section{'[Insert Figure 5 here]'}

The various categories of production losses, as outlined in the OAE diagram, help to highlight the possible areas where losses can be reduced. From the OAE 
diagram the other production loss rates are calculated. The asset effectiveness results are reported on monthly basis, and from the monthly report, yearly performance can be calculated.

\subsection{Company $B$}

Company $B$ is a packaging industry. OEE metrics are used to identify the major drivers of packaging line manufacturing performance and identify areas of process improvement. The defined drivers of manufacturing performance are equipment utilization based on 24 hours per day availability, capacity utilization, overall equipment effectiveness (OEE), and overall production effectiveness (OPE).

The manufacturing performance measurement is based on the equipment timings, and therefore the losses are measured in terms of time losses. It is assumed that the equipment is available to be run for 24 hours per day and 7 days per week. The time usage for the equipment is measured as follows:

\section{The Unscheduled time}

This is defined as the time the equipment is available to run more production. This is the available time due to holidays, mid-week idle time, weekends, and reduced rate due to lack of scheduled demand.

\section{The Scheduled downtime}

This is the time allocated to scheduled activities on the equipment due to planned maintenance or shut downs, meetings, training or breaks, planned cleaning and standby state. 


\section{The 7 major losses}

Seven major time losses can be encountered during the production process. These are due to:

(i) Major stoppages due to machine failure or due to production defect. The stoppage is said to be major if it takes more than 10 minutes. Major stoppages may also result due to supplier related downtime or warehouse downtime.

(ii) Change over from one product to another or from product of one size to another.

(iii) The cutting blade loss, which is the time lost in replacing routine wear parts.

(iv) Start up and shut down losses occurring after annual shutdown, after holidays or weekend, and after lunch and breaks.

(v) Minor stoppages. These are the stoppages that are less than 10 minutes for example due to equipment jams.

(vi) Speed losses, which is the lost equipment capacity resulting from operation at a reduced speed.

(vii) Quality losses due to products that fail to meet specifications.

\section{Running time}

This is the time that is left for production and it is also referred to valuable operating time. Manufacturing losses are presented in the OAE diagram as shown in figure 6. From the OAE diagram, asset (capacity) utilization, OEE and OPE are calculated. 
Asset (capacity) utilization defines how effective an asset is being utilized. The inverse reveals how much more output is available from the current asset if needed today. Thus;

$$
\text { Asset Utilization }=\frac{\text { Loading Time }}{\text { Total Available Time }}
$$

The OEE measure is defined as the ability to run equipment at the designed speed with zero defects. In order to maximise OEE, the 7 major losses should be reduced. Thus;

$$
\mathrm{OEE}=\frac{\text { Valuable Operating Time }}{\text { Operating Time }}
$$

\section{'[Insert Figure 6 here]'}

Finally, the overall production effectiveness (OPE), measures how well the supply chain is effectively utilizing the manufacturing assets. Thus, the OPE measure considers planned downtime and unscheduled time in addition to 7 major losses, as supply chain losses. Thus;

$$
\mathrm{OPE}=\frac{\text { Valuable Operating Time }}{\text { Total Available Time }}
$$

\section{Discussion on the existing tools}


The literature review on OEE evolution reveals a lot of differences in formulation of equipments' effectiveness. The main difference lies in the types of production losses that are captured by the measurement tool. Though the original OEE tool identifies six major losses in a production set up, other types of losses have been found to have a significant contribution to the overall production loss.

In the TEEP tool (see fig. 2 \& 3), a lot of emphasis is given to the influence of machine failure and maintenance on plant productivity. Planned downtime is included to show the percentage time and production lost due to shutdown maintenance. Specialised attention is given to unscheduled downtime and the related metrics like the mean time between failure (MTBF) and mean time to repair (MTTR). The analysis and improvement of the plant based on these metrics enables the maintenance function to improve the functional performance and process capability of the plant. Like OEE, it also includes losses related to quality and speed. However, the tool only considers losses in the operational level of the plant. It is therefore limited to individual equipment or continuous process effectiveness.

The PEE tool for continuous process (see fig. 4) also measures the scheduled and unscheduled downtime due to maintenance. However, it goes further and measures losses to due commercial demand and transaction losses. These losses are included to show the percentage of time the machine is down due to lack of demand. In total, it measures both operational and commercial related losses. 
The industrial examples of OAE application also reveal a big difference in elements included in production loss identification. For example in company A, different categories of losses have been defined (see fig.5). These includes losses related to commercial, internal and external reasons, changeovers, speed losses and quality problems. It groups, for example, all internal losses in one category without giving specialised attention to individual causes. This may not be effective means of measurement because each type of loss requires special attention and corrective action. Company A considers all types of production losses but lacks a clear method of classifying the individual losses and therefore, the measurements cannot effectively support continuous improvement. Company B, on the other hand, has a complete breakdown of all the operational type of losses (see fig 6). It identifies seven major losses, which together with scheduled and unscheduled downtime constitute all the operational production losses. However, it does not consider production losses due to commercial demand fluctuation or losses due to other internal business or external reasons. These differences lead to development of overall production effectiveness framework.

\section{In search of general framework for OAE /OPE measurement}

The differences in the measurement of equipment's effectiveness, in both literature and practice, leads us to two important and enduring research questions in performance measurement cited by Neely et al (2005). These questions are: 
(1.) What needs to be measured?

(2.) How will it be measured?

The first question seeks to know the various factors that influence performance that need to be monitored through a measurement system. The second question includes issues such as measurement scale being used, the data source, and the frequency of measurement. It is noted in literature that the way in which these questions are answered can influence the validity, reliability, and practicality of any measure (Thorndike and Hagen, 1969).

\subsection{Factors to be measured}

A framework for identifying different types of losses for overall production /asset effectiveness is proposed as shown in figure 7 . The framework classifies production losses into different categories depending on the cause of loss. This classification helps the decision maker to measure different causes of production losses so that attention can be given to the relevant causes. It also gives a standardised way of measuring asset effectiveness. The following production loss categories are defined:

\section{'[Insert Figure 7 here]'}

Losses due to external reasons - These are production losses caused by factors that are beyond the control of the company. Among them is: 
(a) Commercial Demands - This is the production loss encountered when there is no demand in the market. This may result to plant shutdown or lower production rates.

(b) Logistic Problems - These are production losses caused by logistics related problems. Among them is third party failure to supply, transport problems resulting to delay in raw material arrival and shortage of utility like electricity, gas or water.

(c) Environmental Regulations - These are losses related production quotas due to environmental degradation. For example restriction on the amount of carbon dioxide emissions can limit the production quantity. This forces the plant to produce below capacity and therefore amounts to production loss.

(d) Natural causes - These are production losses that result from natural causes like poor weather condition.

\section{Losses due to internal reasons - These are production losses caused by} factors within the control of the company. These causes should be analysed and corrective action taken to minimise the losses. Two major categories of these types of losses are business related and operation related losses.

(a) Business related losses - These are production losses resulting from problems at entire business level. Among them is:

- Internal logistics problems like shipping and storage of the finished goods. This may cause production to slow down or shut 
down for a while. Production can also be slowed to control the amount of finished goods stocks.

- Organization problems or labour unrest will cause the production to shutdown leading to production loss.

- Environmental, health and safety problems cause production to be slowed down or stopped.

- Capital projects within the plant forces production to be stopped until they are finished.

(b) Operation related losses - These are production losses encountered in the cause of running the plant. They are the most regular problems encountered in production and therefore, they are the most analysed losses. They include the six major losses cited in literature (Nakajima, 1988) and the scheduled downtime. Due to their chronic nature of occurrence, much of the study on equipment effectiveness is directed towards them.

\begin{abstract}
Among the operational related losses is the unscheduled downtime due to machine failure. The equipment failure downtime determines the equipment availability and this is defined as the period of time a machine can actually be used for production purposes. The availability rate is determined by three factors namely reliability, maintainability and maintenance readiness (Fleischer et al, 2006). The reliability factor is the length of time equipment is able to run without failure and is measured by mean time between failure (MTBF). Maintainability is the length of time an equipment can be brought back to
\end{abstract}


operating condition after it has failed and is measured by the mean time to repair (MTTR). Since it is the responsibility of maintenance function to ensure the availability of production equipment, the availability rate is related to maintenance effectiveness.

The other important time loss is changeover time and replacement of routine wear parts time. Though the changeover time varies from one operation to another, it takes considerable amount of time that requires analysis and reduction. The other major losses are minor stoppages, idling time, reduced speed and quality defects that have been discussed in the literature review. Specialised measurement, analysis and reduction of each of these losses is key in improving the equipment effectiveness.

The inclusion of all these causes of production losses in the OAE calculation gives a complete picture of overall production effectiveness and supports decision makers in identifying areas where improvement is necessary. The unscheduled time is included to show the unutilized capacity and the available output from the current assets. Clear differences between OEE, TEEP, PEE and OPE are also shown in figure 7 and the type of losses each of them includes.

As shown in figure 7 , effectiveness measures can be analysed from equipment level (OEE), operation level and at overall production or factory level. OEE is defined as a measure of ability to run equipment without failure, at the designed speed and with zero defects. It is therefore concluded that only the production 
losses related to equipment should be used to calculate the overall equipment effectiveness (OEE). Scheduled downtime should therefore not be used in OEE calculation.

\subsection{How to measure OEE}

This is an important aspect that addresses the measurement scale, data source and measurement frequency. The validity and usefulness of OEE measure is highly dependent on the data collection and accuracy. Data collection is an important phase of performance measurement and continuous improvement since what has not been measured cannot be improved. It has been claimed that many manufacturing companies measure efficiency of their lines in such a way as to 'mask' many of the causes of lost efficiency (Parsec, 2005). This is due to inadequate data collection or inaccuracy in data recording. Data collection and accuracy is a big challenge for many companies. It is reported in literature (Ericsson, 1997) that accurate equipment performance data is essential to the success and long-term effectiveness of TPM activities. If the extent of equipment failures and production losses are not entirely understood and measured, then TPM actions cannot be deployed optimally to solve major problems or arrest deteriorating performance.

Jonsson and Lesshammar (1999) propose that data collection should be at such detailed level that fulfils its objective without being unnecessarily demanding of resources. The difficulty of data collection is dependent on the complexity of the manufacturing system and whether the data collection is manual or automated. 
For manual data collection, accuracy is very low since recording of some minor stoppages or downtime can often be forgotten. Though the cost of manual data collection is minimal, detailed manual data collection may demotivate the personnel and lead to reaction against the measurements. With the use of MES (manufacturing execution system) and ERP (enterprise resource planning), collection of OEE related data is automated in some manufacturing enterprises. Though the cost associated to these installations is considerable, the data accuracy is high and the data collection process is simplified. Introduction of these modern software tools is been leveraged to produce sophisticated real time reports that allow manufacturers to fully understand all their sources of lost productivity (Parsec, 2005). With the adoption of these new automated technology of data capturing, the areas of lost production time will be easily identified.

To measure production losses using OEE, two units can be used: the production output (tonnage) loss and production time loss. Quality and speed losses are calculated using production output while availability is calculated using downtime. Recording of individual production time loss is the most practical measurement method in many production systems. The frequency of measurement varies from one industry to another. For automated data collection, OEE values can be calculated on real time. The values can then be summarised on hourly and daily basis. For manual data collection, losses (production time and rejects) should be recorded on real time. Then OEE values can be summarised on daily basis. From the daily values, weekly and monthly values can be calculated. A current survey on manufacturing companies 
(Aberdeen Group, 2006) indicates that best in class companies are not only more vigilant and persistent in their measurement efforts but also monitor and measure their performance more frequently. The survey indicates that operational measures such as OEE, for such companies is monitored daily, at minimum, in order to trigger effective corrective or preventive action.

\section{Conclusion}

From the analysis of the OEE tool, its evolution and application in the industries, it is concluded that OEE is a valuable measure that gives information on the sources of lost time and lost production. Many companies routinely hit capacity constraints and immediately consider adding overtime for existing workers, hiring worker for new shift or buying new production line to boost their production capacity. For such companies, OEE tool can help them to optimize the performance of the existing capacity. It is a valuable tool that can help management to unleash hidden capacity and therefore reduce overtime expenditures and allow deferral of major capital investment. It aids in reducing process variability, reducing changeover times and improving operator performance. These are measurable benefits that substantially improve the bottom line of production operation and enhance the companies' competitive edge.

It is shown that OEE has evolved to include others production losses that were not originally included. This has lead to development of new terminologies like TEEP, PEE, OPE, OAE and OFE. The difference between these terminologies 
or tools is based on the type of production losses included as shown in figure 8 . It was also found that the industrial application of OAE varies from one factory to another. This is dependent on the types of production losses important to each company. From industrial examples analysed, it was found that specialised attention of important losses was lacking. In some cases, some important types of losses were completely left out.

To harmonise the differences in literature and in practice, a framework for measuring the production losses has been developed. This framework proposes three levels of effectiveness measurement namely equipment level effectiveness (based on original OEE), operational level effectiveness (based on TEEP) and business level effectiveness (OAE/OPE). Due to the chronic nature of the operational causes of production losses, pertinent rates like availability, performance rate, quality rate, scheduled downtime rate, etc needs to be highlighted to enable specialised attention to the particular losses. The framework also identifies losses due to business related problems like stock control, storage or shipping problems and other non-operational related causes. It proposes measurement of production losses due to external reasons. This may be due to lack of demand, logistics problems (e.g. supplier or transport failure, utility shortage), environmental regulations or natural causes. The framework leaves room for customization with respect to losses that need specialised attention. The inclusion of all types of losses in the OAE tool gives management complete information for well-informed decision making. 
It is also concluded that the OAE tool is best suited in measurement of individual equipments, discrete-type processes and in continuous processes effectiveness. This is beneficial in high volume process based manufacture where capacity utilisation is of high priority and stoppages or disruptions are expensive in terms of lost capacity (Bulent et al, 2000). However, deployment of OEE in low volume job shops and some batch processes is not very beneficial. Due to the nature of these processes, the unscheduled production time is high and thus planned maintenance can take place then. Also, failure of one machine does not have a big impact because production can be re-routed to another machine. The change-over time is not relevant since set-up can be done on one machine as production continues on the other. For production processes with buffers in between, OEE would need to be redefined since downtime on one process stage does not directly affect the next stage.

Finally, the accuracy of the OEE data is very important. The use of OEE as a production measure necessitates accuracy in the performance data collected. Without accurate data, the OEE measure can easily lead to lack credibility. It is therefore important to invest time and money in improvement of data collection. Data collection can also be highly improved by embracing new automated technology of data collection.

\section{Elements of further research}

The performance elements measured by OEE tool, though important, are not sufficient to describe the effectiveness of a product system. Some important 
measures (e.g. cost and flexibility) are not measured in the OEE. Further research should explore the dynamics of translating equipment effectiveness or loss of effectiveness in terms of cost. Though this possibility is on case-to-case basis, the cost translation of OEE will have more significance to management. Due to importance of data accuracy in OEE calculations, further research should include cost and benefits of investing in automated data collection methods. 


\section{$\underline{\text { References }}$}

Aberdeen Group, The manufacturing performance management benchmark report, Aberdeen group Inc, Boston, MA, June 2006

Bulent D., Tugwell P., Greatbanks R., Overall equipment effectiveness as a measure of operational improvements - A Practical Analysis, Internal Journal of Operation \& Production Management, Vol. 20, No. 12 pg 1488-1502, 2000

Ericsson J., Distribution analysis - An important tool in lean production, Dept of Production \& Material Engineering, Lund University, Lund, 1997

Fleischer J., U. Weismann, Stephen Niggeschmidt, Calculation and Optimisation Model for Costs and Effects of Availability Relevant Service Elements, Proceedings of LCE2006, 2006

Huang S.H., Dismukes J.P, Mousalam A., Razzak R.B., Robinson D.E, Manufacturing Productivity improvement using effectiveness metrics and simulation analysis, International Journal of Production Research, Vol 41, No. 3 Pg 513 - 527, 2003

Huang S., Manufacturing System Modelling for Productivity Improvement, Journal of Manufacturing System, 2002 issue, pp 1-9, 2002

Ivancic I., Development of Maintenance in Modern Production, Euromaintenance '98 Conference Proceedings, CRO, 1998

Jonsson P., Lesshamar M., Evaluation and Improvement of Manufacturing Performance Measurement Systems - The Role of OEE, International Journal of Operations \& Production Management, Vol. 19, No.1, pp 55-78, 1999 
Nakajima,S., Introduction to TPM: Total Productive Maintenance, Cambridge, MA, Productivity Press, 1988

Neely A., Mike Gregory, Ken Platts, Performance Measurement System Design: A Literature Review and Research Agenda, International Journal of Operations \& Production Management, Vol. 25, No 12, pp 1228-1263, 2005

Neely, A.D, The performance measurement revolutions: Why now and where next, International Journal of Operation \& Production management, Vol 19, No 2, pp 205228, 1999

Oechser R., Pfeffer M., Pftzner L., Binder H., Muller E., Vonderstrass T., From Overall Equipment Effectiveness to Overall Fab Effectiveness (OFE), Material Science in Semiconductor Processing, Vol 5, Issue 4-5, pp 333-339, 2003

Parsec Automation Corp, The hidden pitfalls of doing back of the envelope calculations to determine your current OEE, Available online at: www.parsec-corp.com, CA, 2005 (accessed June, 2006)

Pintelon L., Gelders L., Puyvelde F.V, Maintenance Management, Acco, Leuven, Belgium, 2000

Porter M., The Value Chain and Competitive Advantage, New York Free Press, 1985

Raouf A., Improving Capital Productivity Through Maintenance, International Journal of Operations \& Production Management, Vol. 14, No. 7 pp 44-52, 1994

Scott D., Pisa R., Can Overall Factory Effectiveness Prolong Moore's Law?, Solid State Technology, Vol 41, No 3, pp 75 - 82, 1998 
Thorndike, R.L., Hagen E., Measurement and Evaluation in psychology and Education, Third Edition, John Wiley \& Sons, New York, 1969

Williamson R.M., Using Overall Equipement Effectiveness: the Metric and the Measures, Strategic Work Systems, Inc. Columbus, Available online at: www.swspitcrew.com, (accessed June, 2006)

Wilson A., Asset Maintenance Management - A Guide to Developing Strategy \& Improving Performance, Conference Communication, 1999

U.S Department of Energy, How to Measure Performance: A Handbook of technics and Tools", 1995 


\section{List of Figures}

Figure 1: The OEE measurement tool and the perspectives of performance integrated in the tool

Figure 2: Constituent elements used in the calculation of TEEP

Figure 3: The TEEP diagram and its constituent elements

Figure 4: The general outline of PEE diagram for continuous process

Figure 5: The OAE diagram of company A showing the production losses

Figure 6: The OAE diagram of Company B

Figure 7: Classification of Production losses for calculating overall production effectiveness 


\section{Performance Measurement Using Overall Equipment Effectiveness (OEE): Literature Review \& Practical Application Discussion}

\section{Figures}

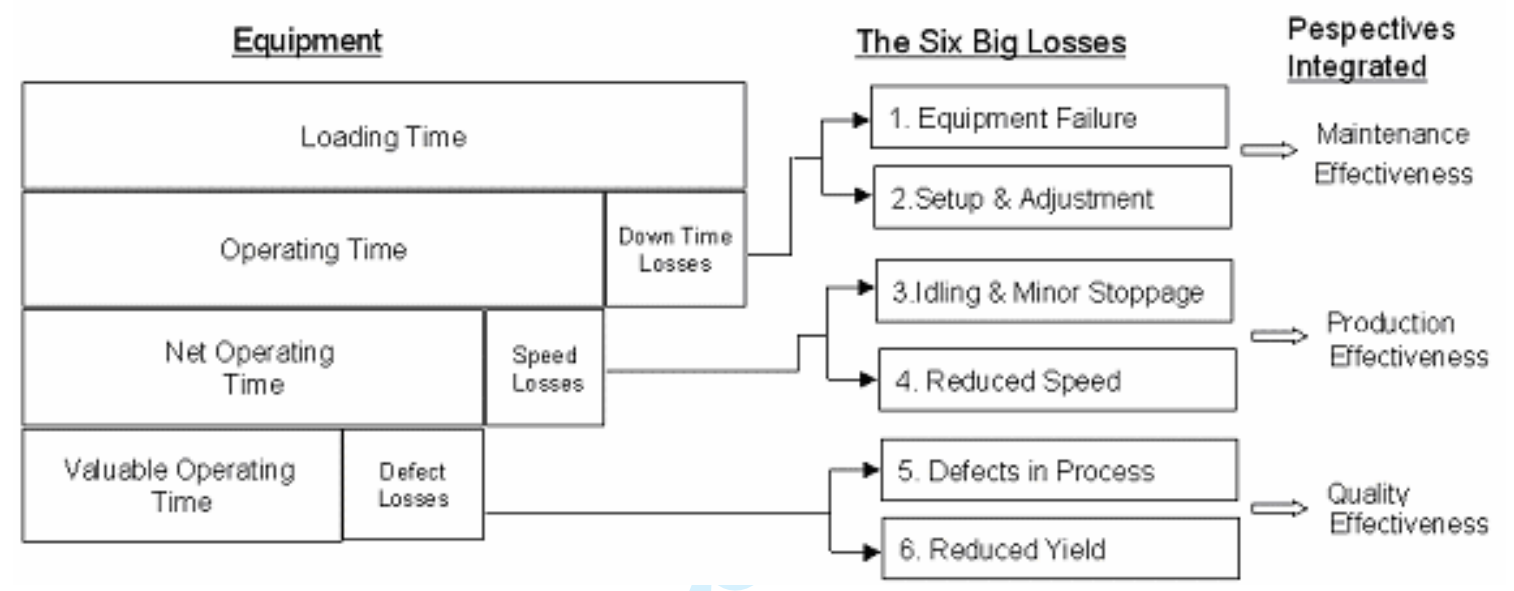

Figure 1: The OEE measurement tool and the perspectives of performance integrated in the tool 


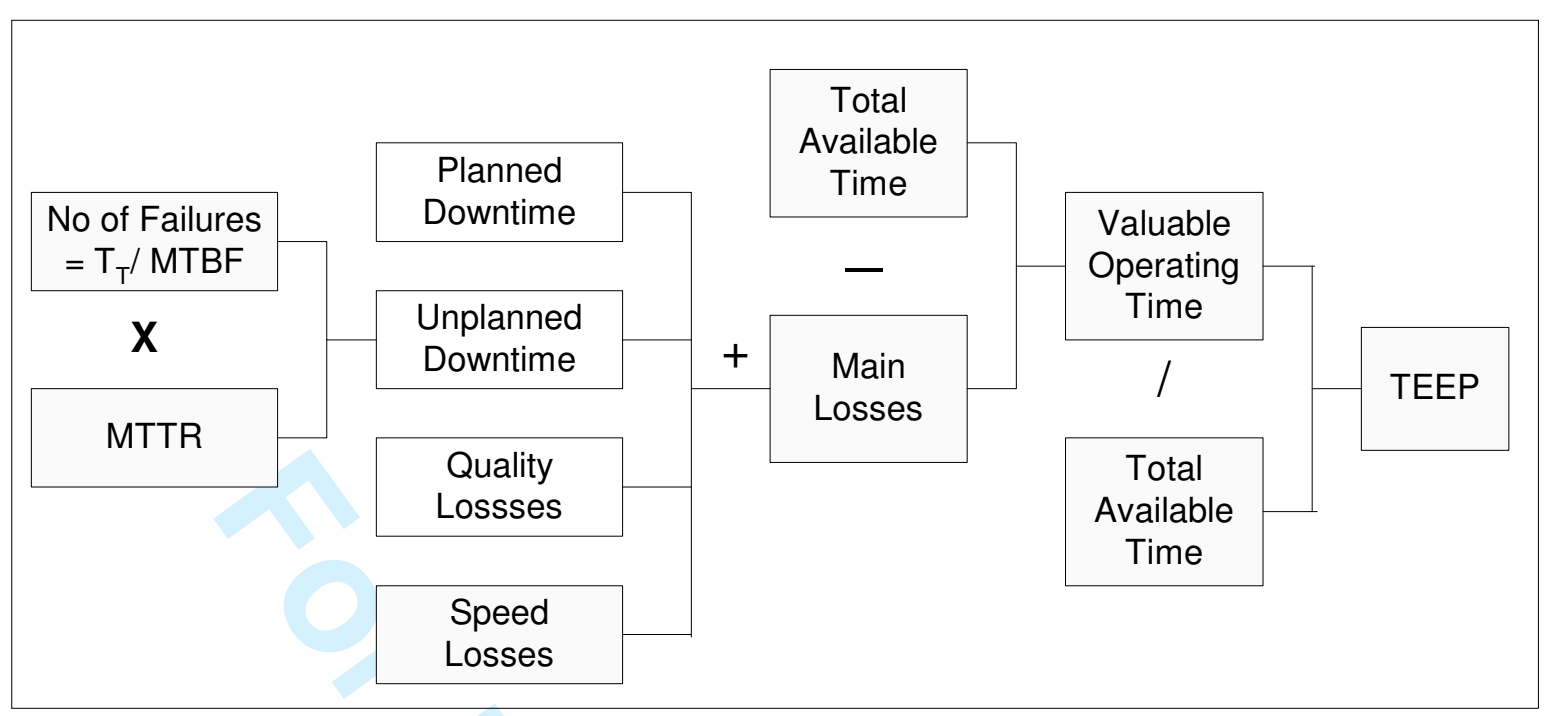

Figure 2: Constituent elements used in the calculation of TEEP 
Figure 3: The TEEP diagram and its constituent elements 


\begin{tabular}{|c|c|c|c|c|c|c|c|}
\hline \multicolumn{7}{|c|}{ Planned time } & \multirow{7}{*}{$A_{1}$} \\
\hline \multicolumn{6}{|c|}{ Scheduled Operating time } & $\begin{array}{l}\text { Scheduled } \\
\text { Downttime }\end{array}$ & \\
\hline \multicolumn{5}{|c|}{ Net Operating time } & $\begin{array}{l}\text { Unscheduled } \\
\text { Downttime }\end{array}$ & $\mathrm{A}_{2}$ & \\
\hline \multicolumn{4}{|c|}{ Loading time } & $\begin{array}{l}\text { Rate } \\
\text { Loss }\end{array}$ & $E$ & & \\
\hline \multicolumn{3}{|c|}{ Product Support time } & $\begin{array}{l}\text { Yield } \\
\text { Loss }\end{array}$ & QR & & & \\
\hline Net Productive time & $\begin{array}{l}\text { No Demand } \\
\text { Time }\end{array}$ & $\begin{array}{l}\text { Transaction } \\
\text { losses }\end{array}$ & & & & & \\
\hline & OU & PSE & & & & & \\
\hline
\end{tabular}

Figure 4: The general outline of PEE diagram for continuous process 


\begin{tabular}{|c|c|c|c|c|c|c|c|}
\hline \multicolumn{7}{|c|}{ Theoretical Tonnage $\left(T_{T}\right)$} & \multirow{3}{*}{$\begin{array}{l}\text { Lack of Commercial demand } \\
\text { Change-over losses }\end{array}$} \\
\hline & & & & & & $\mathrm{PL}_{\text {сом }}$ & \\
\hline & & & & & $\mathrm{PL}_{\mathrm{CH}}$ & $\mathrm{PL}_{\text {сом }}$ & \\
\hline & & & & $\mathrm{PL}_{\mathrm{FE}}$ & $\mathrm{PL}_{\mathrm{CH}}$ & $\mathrm{PL}_{\text {COM }}$ & External Lack of reliability \\
\hline & & & \multirow[t]{4}{*}{$\mathrm{PL}_{\mathrm{FI}}$} & & & & Internal Lack of reliability \\
\hline & & & & $\mathrm{PL}_{\mathrm{F}}$ & $\mathrm{PL}_{\mathrm{CH}}$ & $\mathrm{PL}_{\text {сOM }}$ & $\begin{array}{l}\text { Total Lack of reliability } \\
\text { (Internal + External) }\end{array}$ \\
\hline & & $\mathrm{PL}_{\mathrm{OP}}$ & & $\mathrm{PL}_{\mathrm{F}}$ & $\mathrm{PL}_{\mathrm{CH}}$ & $\mathrm{PL}_{\text {сом }}$ & Lack of operating performance \\
\hline Actual Tonnage $\left(T_{A C T}\right)$ & $\mathrm{PL}_{\mathrm{Q}}$ & $\mathrm{PL}_{\mathrm{OP}}$ & & $\mathrm{PL}_{\mathrm{F}}$ & $\mathrm{PL}_{\mathrm{CH}}$ & $\mathrm{PL}_{\text {сOM }}$ & Quality Problems \\
\hline
\end{tabular}

Figure 5: The OAE diagram of company A showing the production losses 


\begin{tabular}{|c|c|c|}
\hline \multicolumn{2}{|c|}{ Total Available Time $\left(T_{T}\right)$} & \\
\hline \multicolumn{2}{|c|}{ Loading Time } & Unscheduled Time \\
\hline \multicolumn{2}{|c|}{ Operating Time } & Scheduled Downtime \\
\hline & \multicolumn{2}{|c|}{ Major Stoppage } \\
\hline & \multicolumn{2}{|c|}{ Minor Stoppage } \\
\hline & \multicolumn{2}{|c|}{ Cutting Blade loss } \\
\hline & \multicolumn{2}{|l|}{ Change Overs } \\
\hline & \multicolumn{2}{|c|}{ Start up/ Shut down } \\
\hline & \multicolumn{2}{|l|}{ Speed Losses } \\
\hline Valuable Operating Time & \multicolumn{2}{|c|}{ Quality Losses } \\
\hline Running Time & & 7 Major Losses \\
\hline
\end{tabular}

Figure 6: The OAE diagram of Company B 


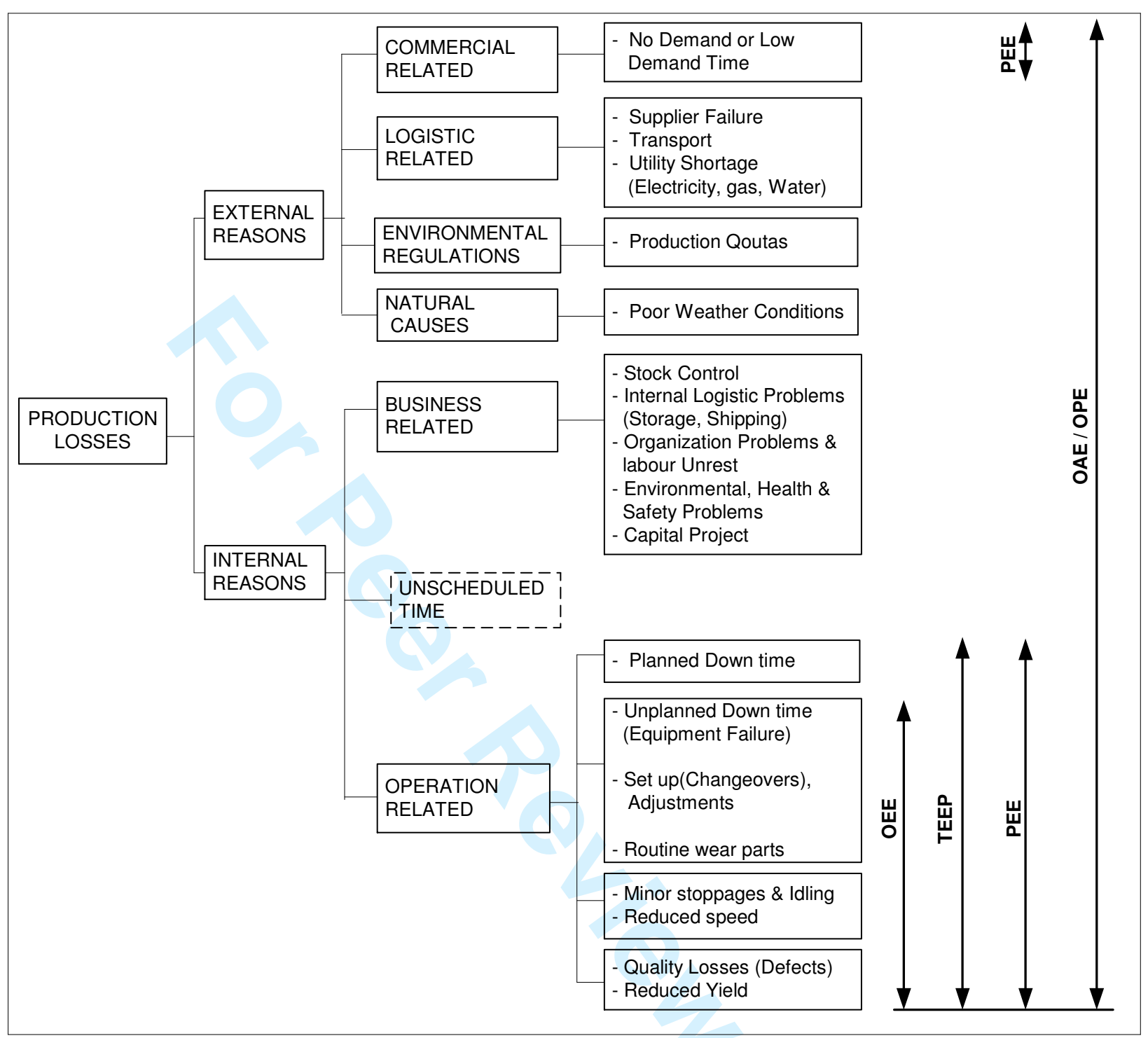

Figure 7: Classification of Production losses for calculating overall production effectiveness 